\title{
LOS CARACTERES DE LA POLÉMICA CRISTIANA CONTRA EL ISLAM ENTRE BASILEA Y TRENTO
}

\author{
POR
}

\author{
BeAtrIZ Alonso ACERo
}

CEH-CSIC

\begin{abstract}
RESUMEN
El artículo aborda los rasgos fundamentales de la polémica cristiana contra el Islam en la segunda mitad del siglo XV y en la primera del XVI, atendiendo a la doble perspectiva en que se puede dividir su estudio. Por un lado, la postura de enfrentamiento entre las dos religiones, basada en la concepción cristiana del Islam como doctrina falsa desde su revelación y cargada de errores en la práctica. Por otro, la actitud más conciliadora, que también reconoce al cristianismo como única doctrina verdadera pero busca una aproximación a los musulmanes con intención evangelizadora. Dentro de cada postura se atiende a sus autores más representativos y a la plasmación práctica de los postulados teóricos, en especial en la España de comienzos del siglo XVI.
\end{abstract}

\section{Abstract}

This article studies the characteristics of Christian controversy against Islam between 1450 and 1550 . There are two principals attitudes. The first one is a position of total confrontation between both religions, because of Christianity describes Islam as a false doctrine since its own revelation. The second one is the attitude of conciliation. This one also recognizes Christianity as the only true doctrine, but it looks for the aproximacion to muslims with a purpose of evangelization. The article studies the most important authors of each position and the starting of theoretical postulates specially in Spain during the first decades of XVI ${ }^{\text {th }}$ century. 
En los albores del siglo XVI, una Europa a caballo entre la tradición y la modernidad comprueba la permanencia de la polémica islamo-cristiana, lógica consecuencia del nuevo peligro musulmán que amenaza al viejo continente. Ante la continuidad del enfrentamiento entre ambas culturas, la disputa teológica cobrará un nuevo énfasis en la transición al primer Renacimiento. Aunque en esencia conserve los rasgos y caracteres fijados en la época medieval, los nuevos tiempos y coyunturas acabar por perfilar una polémica específica en la que España, abocada a la convivencia en su propio suelo con el Islam, genera caracteres propios y diferenciados a los del resto de Europa. A pesar de la continuidad de la diatriba religiosa, su estudio para los años finales del siglo XV y las primeras décadas del XVI no ha gozado de excesivo interés, quizás por la propia consideración de la polémica moderna como simple continuación de la establecida en los siglos medievales. En los últimos años, tan sólo autores como L. Cardaillac, o M. Á. de Bunes han forjado las líneas a seguir en el estudio de este tema para los siglos XVI y XVII desde el punto de vista de las fuentes cristianas, mientras que A. Echevarría acaba de hacer lo mismo con respecto al complejo, pero decisivo, siglo XV. Es en este marco historiográfico donde queremos insertar este análisis, centrándonos en un período histórico de especial relevancia, en el que se forjan y fortalecen ritmos y escenarios que definen coordenadas religiosas, teológicas y espirituales que estarán presentes, aunque en continua evolución, al menos hasta el advenimiento del llamado «siglo de la razón».

A pesar del gran desarrollo que la polémica cristiana contra el Islam irá adquiriendo en el Occidente europeo en los siglos medievales, to cierto es que sus orígenes hay que situarlos en la Bizancio del siglo VIII. Hostigada por la presión que ejercen los árabes en el norte de África, en las islas de Mediterráneo oriental y en Asia Menor, ve emerger a una figura del relieve de san Juan Damasceno (m. 750), que representa la primera reacción cristiana hacia la religión musulmana, convirtiéndose según N. Daniel, en el fundador de la tradición cristiana en la polémica anti-islámica ${ }^{1}$. Cuando el Islam empieza a penetrar en el Oriente europeo, la teología cristiana ya ha alcanzado un considerable grado de definición de sus dogmas y presupuestos doctrinales, a partir de la Sagrada Escritura y de la aplicación de un discurso racional. El Islam, a los ojos de San Juan, no puede ser una amenaza real para una doctrina con una base teologica tan seria y rigurosa como la que tiene el Cristianismo y que él ha contribuido a asentar con firmeza a través de su síntesis de la doctrina patrística anterior a él. El último de los Santos

I N. DANIEL, Islam and the West. The making of a image. Edimburgo, 1960, p, 3. Esta obra sigue siendo referencia fundamental para conocer los caracteres de la polémica entre Cristiandad e Islam en los siglos del medievo.

Proyección internacional de la iglesia hispana Hispania Sacra 51 (1999) 
Padres de Oriente estima que el peligro árabe y la controversia con la religión musulmana son pasajeros. Aún así, se molesta en establecer en su Dialexis una auténtica guía de la disputa contra musulmanes, siendo él el primero en aplicar la técnica de la argumentación, tradicional entre los cristianos, a la refutación del Corán. San Juan fija con nitidez lo que es herejía y lo que entra dentro de la más pura ortodoxia cristiana; temas que luego se convertirán en habituales dentro de la polémica anti-islámica, como el de la Trinidad o la conducta de Mahoma en vida ya aparecen en sus escritos, demostrando con ello hasta qué punto, aunque no estima que el Islam pueda ser una amenaza para el Cristianismo, le preocupa que la nueva religión que ha surgido con la revelación a Mahoma esté entrando en contacto con los herederos del Imperio romano de Occidente.

El mayor o menor grado de reacción de estos autores bizantinos ante la llegada del Islam apenas tiene repercusiones en el Occidente europeo a causa del desconocimiento de la lengua griega en Poniente. En estas latitudes del continente europeo es la España medieval la que marca la pauta en lo que se refiere a los inicios de la polémica religiosa, al ser el territorio donde se dieron los primeros contactos entre Cristiandad e Islam, en los inicios del siglo VIII, de la misma forma que en los estertores del siglo XV abre el camino al final de la presencia musulmana en la Europa occidental. Sin embargo, los primeros textos polémicos no aparecen en España hasta siglo y medio después de la entrada de los musulmanes en la Península, y lo harán precisamente en el seno de la comunidad mozárabe cordobesa, fiel representante de las relaciones establecidas entre Cristiandad e Islam en la España medieval conquistada por las armas musulmanas. Será en los años centrales del siglo IX cuando figuras como el abad Esperaindeo, máximo exponente del renacimiento religioso y teológico de los mozárabes de Córdoba, y sus discípulos san Eulogio y Álvaro de Córdoba, se coloquen en la vía de la realización de estudios de la llamada «secta mahometana" y de su religión con el propósito de realizar una refutación en toda regla. La defensa que todos ellos hacen de la doctrina cristiana lleva implícito un fuerte ataque al islamismo y a su fundador, que les inspira obras apologéticas de gran contenido crítico contra los musulmanes, como el Memoriale martyrum de san Eulogio, al tiempo que ensalzan a todos aquellos que, como el propio santo cordobés, acabarían muriendo mártires de esta encarnizada lucha contra la fe enemiga. Sin embargo, habrá que esperar al siglo XII para que sea apreciable un cierto cambio de enfoque en la manera en la que hasta entonces estaba planteada la diatriba contra el Islam. La nueva orientación surge precisamente fuera de España, en una Europa Occidental aún poco preocupada por el Islam. Pedro el Venerable, abad de Cluny, ejemplifica el primer intento formal de conocer el Islam desde sus más profundos presupuestos doctrinales, intento en el que no faltan los deseos de combatir a la fe 
del adversario, pero, al menos, a partir de un estudio riguroso del mismo ${ }^{2}$. Es en el transcurso de un viaje a España en el año 1141 cuando este clérigo francés, encarga a Roberto de Ketene la primera versión latina del Corán, acabada dos años después. A pesar de sus errotes, esta traducción alcanzaría gran predicamento en la Europa occidental de los siglos siguientes, haciéndose una reedición del texto en 1543 a cargo de Bibliander, uno de los discípulos más aventajados de Zwinglio.

En estos orígenes occidentales de la polémica anti-islámica y ya hasta los siglos XVI y XVII estará muy presente en los textos la figura de san Isidoro, como máximo exponente que es del mundo cristiano en la España medieval. Su categoría de alter-ego en Occidente de lo que representa san Juan Damasceno en Oriente y su configuración posterior como símbolo del empuje de las armas cristianas contra el Islam lo sitúan como referencia obligada de esta diatriba religiosa. Aunque por la fecha de su muerte, el año 636, no llegó a entrar en contacto directo con Mahoma, la leyenda medieval forjada en tomo suyo retoma el hilo de las profecías a él atribuidas sobre la pérdida de la España visigoda a manos de los musulmanes por causa de la inobservancia de las leyes divinas y eclesiásticas y acaba colocando al santo al lado de Santiago matando también a moros a lomos de otro caballo blanco ${ }^{3}$.

Desde este siglo XII hasta el final del Cuatrocientos España es una perfecta síntesis de un proceso que comienza a ponerse en marcha en los inicios de la presencia musulmana en la Península. Durante ocho siglos se va obrando el cambio que supone el paso del «silencio» cristiano ante la superioridad musulmana y del «silencio» musulmán por el hermetismo en el que se encierra precisamente a causa de su superioridad en tierra ajena, a un progresivo y lento despertar del espíritu cristiano contra el invasor. El interés hacia el Islam, aun siendo todavía escaso, aumentará conforme la reconquista vaya dando frutos en el bando cristiano, como única fórmula para poder desmontar desde su base los puntos doctrinales básicos del credo isłámico. Así van surgiendo intentos de aproximación como los protagonizados por Rodrigo Jiménez de Rada, coordinador de la Historia Arabum o por el canónigo Marcos de Toledo, que vuelve a hacer una nueva traducción de Corán que, sin embargo, no alcanzó la

2 R.W. SOUTHERN, Westem Views of Islam in the Middle Ages. Cambridge-Massachusetts, 1962.

3 J. LOPEZ ORTIZ; O.S.A., San Isidoro de Sevilla y el Islam. (Comentarios a cuatro pasajes de don Lucas de Tuy y del Silense). Madrid, 1936. El autor refiere la importancia que los escritores de los siglos medievales dieron al tema del posible encuentro entre san Isidoro y Mahoma. El propio Pedro el Venerable creyó en la estancia de Mahoma en España, pero no se habría encontrado con el santo cristiano, porque éste se hallaba en Roma en por aquel entonces; en cuanto éste regresó a España, Mahoma fue avisado por el diablo (el Gabriel del Corán) huyendo a tiempo. Sólo en la Summa historialis de San Antonino, compuesta en Florencia a mediados del siglo XV, se realiza el encuentro entre ambos personajes.

Proyección intemacional de la iglesia hispana Hispania Sacra 51 (1999) 
difusión de la realizada por Ketene. En esta misma línea se sitúa el propio Alfonso X, demostrando que este interés no sólo alcanza al estamento eclesiástico. El monarca encarga que se recoja en su Crónica General la vida y obra de Mahoma, y más allá de la propia polémica, procede a la fundación de una cátedra de árabe en la Universidad de Sevilla. A todos ellos habría que unir, ya en la segunda mitad del siglo XIII, la labor desempeñada por las Ördenes Mendicantes, especialmente dominicos y franciscanos, en su intento de hacer conocer la lengua y costumbres de los adeptos al Islam a sus frailes para luego poder convertir con más facilidad a los infieles. Figuras como las del franciscano mallorquín Ramón Llull se insertan en este marco de vocación misional respecto al musulmán. Ahora bien, este progresivo interés hacia el Islam y sus presupuestos teológicos no tiene nunca un carácter conciliador, sino claramente hostil. La concepción cristiana del Islam cono doctrina falsa y engañosa justifica la decisión de expulsar al infiel de la Península ante la inexistencia, aún, de una conciencia de posible convivencia forzosa con el musulmán. Otra cosa muy distinta será la conciencia real y cotidiana en la que la vida de frontera sitúa a las dos religiones que comparten el suelo peninsular, sin olvidar la presencia de la comunidad judía en la España medieval.

Los inicios del Quinientos marcan una coyuntura histórica de orto y ocaso para el Islam en Europa. Mientras que en Occidente las armas cristianas se han apoderado del bastión nazarí en la Península Ibérica, las huestes otomanas avanzan hacia Poniente en un empeño decisivo que encuentra su gran aldabonazo en la conquista de Constantinopla en 1453. Es la Europa forjadora de estados la que revive la amenaza musulmana en un momento en que el espíritu de cruzada que había animado tiempos pasados se halla desvaído por una eclosión de un nuevo sentir en el que el hombre se convierte en centro del universo. Sólo el Papado guarda el impulso necesario para convocar a la Cristiandad a una nueva empresa en el Cercano Oriente, pero aún así, la respuesta a sus llamadas ya nunca volverá a organizar a los príncipes cristianos al frente de una amenaza común. Los nuevos tiempos anteponen intereses políticos y económicos a los viejos ideales cruzados y la reacción frente al nuevo embate del Islam en Levante reviste caracteres de individualidad frente a las empresas colectivas del pasado. Tan sólo cuarenta años después de la entrada de Mehmet II en la ciudad del Bósforo, las capitulaciones de Santa Fe dan paso a la rendición del último rey nazarí de Granada. La frontera marítima y terrestre entre Cristiandad e Islam entrará en el Quinientos bajo la impronta de unos nuevos presupuestos que la hacen distinta, aunque nunca olvida los rasgos que la forjaron a lo largo de la Edad Media.

Conforme han avanzado los siglos del medievo las críticas entre el bando cristiano y el musulmán se han ido tornando en auténticas diatribas cargadas 
de virulencia y acritud. En Europa, el cada vez más peligroso empuje otomano supone que, liegados al siglo XV, la mayor parte de las obras escritas con el Islam como tema principal se dirijan fundamentalmente a los propios cristianos, alejándose de los propósitos doctrinales y evangelizadores sobre los musulmanes que habían tenido en los últimos tiempos. Lo que se intenta es que la presencia real o potencial del Islam en tierras europeas no conlleve una presión sobre la fe del cristiano que le haga dudar o incluso renegar de sus creencias en un momento dado. La reacción contra el Turco desde la perspectiva de la polémica teológica va a consistir en escritos difamatorios en los que se ataca desde sus mismos presupuestos doctrinales al Islam. Mientras, en España la culminación del proceso reconquistador podría haber supuesto un colofón triunfal al cada vez más arraigado concepto de superioridad del Cristianismo sobre el Islam a partir del cual proceder a una definitiva expulsión del infiel de los límites peninsulares. El hecho de que se abra una vía a la permanencia mediante la conversión forzoșa implica que ese concepto se emplee desde una tendencia a la conciliación que irá evolucionando hacia posturas de mayor intransigencia conforme avance el siglo XVI hasta llegar a la expulsión definitiva de los moriscos entre 1609 y 1614.

Por lo que a la Historia de la Iglesia se refiere, el período a abarcar queda enmarcado por la celebración de los dos concilios generales más relevantes de los siglos modernos. Los ecos del polémico Concilio de Basilea (1431-1449) aún resuenan en Europa cuando llega a Roma la noticia de la pérdida de Constantinopla para la Cristiandad. El enfrentamiento entre los partidarios del poder papal y los conciliaristas marca la evolución de una Iglesia que, ante los embates de la Reforma, se verá obligada a convocar otro concilio en los años centrales del siglo XVI. Los presupuestos luteranos, calvinistas, erasmistas y alumbrados colocan a la Iglesia en una necesaria coyuntura de cambio y renovación, aunque ésta se revista en la mayoría de los casos de una vuelta a la más estricta tradición. En España, la unión de reinos encarnada en la figura de los Reyes Católicos va a suponer la aparición de una Iglesia que prima la unificación religiosa, desechando la oportunidad de poner en marcha un proceso y riguroso de asimilación de los diferentes credos que aún permanecen en la Península hasta 1492.

En la segunda mitad del siglo XV y con una proyección manifiesta a lo largo del Quinientos el Cristianismo se enfrenta al Islam desde una doble perspectiva. De un lado, es evidente que hay una postura teológica de enfrentamiento entre los dos credos, fruto de unos postulados que ya fueron fijados en la época medieval y que permanecen vigentes en el tránsito hacia el primer Renacimiento. A los ojos de la Cristiandad, el Islam no deja de ser una doctrina falsa desde su misma revelación y cargada de errores en su práctica, por lo

Proyección internacional de la iglesia hispana Hispania Sacra 51 (1999) 
que es necesario atacar sus postulados desde la misma base, con toda la beligerancia de la que la pluma de los escritores sea capaz de cargarse y sin ningún tipo de miramientos ni concesiones, máxime ante la nueva complicación política que se cierne sobre Europa por la amenaza otomana. Autores como Alfonso de Espina ${ }^{4}$, Juan de Torquemada ${ }^{5}$, Nicolás de Cusa ${ }^{6}$, en algunos de sus estudios o el propio papa Pío $I^{7}$ son los máximos exponentes de esta posición de enfrentamiento durante este período. Todos ellos parten de una base térica en la que queda clara la falsedad del Islam a partir de la engañosa figura de su profeta y alientan a una nueva empresa contra los infieles en la práctica, a través de la cual dejar para siempre atrás la pesadilla de esta fe simulada. En realidad, como señala Cusa, la visión cristiana hacia los musulmanes no es sino la de instrumento divino a través del cual los seguidores de Cristo paguen por sus pecados y perseveren en el camino de perfección de su fe. El recurso por parte de estos autores a los textos elaborados por quienes les precedieron en la misma lucha es constante, y así se cita de manera continuada a san Isidoro, a Pedro el Venerable o a san Eulogio, aunque en ocasiones las críticas al Islam sean más exacerbadas que las que hicieron las fuentes cristianas en las que beben. Si en los siglos anteriores aún, al menos, se había valorado la capacidad intelectual de los musulmanes, demostrada en sus numerosos y espectaculares avances científicos en campos como la medicina o las matemáticas, estos autores del siglo XV no tendrán reparo en descallficar incluso la inteligencia de los sarracenos, como podemos encontrar en el Fortalicium Fidei de Alfonso de Espina.

Pero, junto a esa postura hostil, en esta segunda mitad del siglo XV es posible observar la presencia de una actitud más conciliadora, que podríamos definir como de aproximación hacia el Islam. Esta línea recogería la herencia de autores medievales como Ramón Llull, Fidencio de Padua o Ricoldo de Montecroce ${ }^{8}$, en tanto en cuanto intentaron un acercamiento al Islam para conocer mejor sus doctrinas. Los postulados por los que se guían estos conciliadores coinciden con los del bando más intransigente en señalar que el Cristianismo es la única doctrina verdadera, pero ello no les impide reconocer que hay un deber religioso de catequizar en la fe cristiana a los que están errados. Este auténtico espíritu misional imbuye a tanto a autores laicos como a representantes de la Iglesia y podemos encontrar su rastro tanto en el Occidente como en el Oriente europeo, aunque ello no significa que ésta sea la posición

\footnotetext{
4 A. de ESPINA, Fortalicium fidei contra fidei christianae hostes. Nuremberg, 1494.

5 J. DE TORQUEMADA, Defensorium fidei contra Indaeos, hereticos et sarracenos, 1473.

6 Vid. la reciente edición de su obra, en N. de Cusa, De concordantia catholica o sobre la unión de los católicos. Madrid, Centro de Estudios Constitucionales, 1987.

7 Pius episcopus servus servorum Dei illustri Mahometi principi turcorum timorem divini nominis et amorem .... 1470.

\& R. de MONTECROCE. Reprobación del alcoran. Reedición en Sevilla, 1501.
} 
teológica dominante durante las décadas finales del Cuatrocientos. En Occidente la figura más relevante es la del teólogo Juan de Segovia, a quien podemos considerar el iniciador de una nueva etapa en la polémica anti-islámica, no tanto por la absoluta innovación de su pensamiento sino más bien por haberlo hecho en un período en el que la tendencia al recrudecimiento de las posiciones parece evidente. Segovia, en un contexto favorable a la oposición más abierta al Islam ante el avance otomano, consigue alzar su voz preconizando un método pacifista en el que la lucha contra la religión musulmana no vendría dada por las armas sino por el conocimiento profundo de la doctrina islámica y a partir de ahí, por los intentos de aproximación a sus fieles practicantes $^{9}$. Como bien ha estudiado Darío Cabanelas, Segovia no se opone con rotundidad al empleo de la fuerza para reducir a los musulmanes, e incluso es favorable a las cruzadas aunque siempre y cuando se trate de un caso de defensa propia y sea una solución temporal, pues no fue propósito de Cristo extender su doctrina mediante el empleo de las armas materiales, sino de las espirituales. Desechada la estricta labor misional, por tratarse de un empeño a muy largo plazo que requeriría de una adecuada formación de los clérigos y una actitud favorable de los musulmanes, Segovia propone un método que bien podríamos llamar pacifista, basado en la tolerancia, a la que se llega mediante el empleo del derecho natural. Según sus ideas, tras lograr en la medida de lo posible la paz con el adversario, se crearía un marco de colaboración entre ambas comunidades para, desde aquí, proceder a una «discusión pacífica de las doctrinas fundamentales que separan a entrambas ideologías, partiendo siempre de los puntos de contacto y nunca de las divergencias» ${ }^{10}$. Si los adeptos al Islam aceptaban este método, se entraría en el buen camino para hacerles caer en la cuenta de los errores de su fe, mostrándoles la verdad de las doctrinas coincidentes con las promulgadas por Cristo; si no lo aplaudían, al menos la Iglesia habría cumplido con su deber de enseñar al errado y serían los musulmanes los que tendrían que cargar el resto de su historia con el peso de su propia falsedad y equivocación.

En la Europa Oriental del siglo XV también es posible encontrar ejemplos de esta postura de aproximación al Islam. En un momento de transición a esta centuria hay que situar las conversaciones de Manuel II Paleólogo con un profesor (Mudarris) musulmán de Ankara ${ }^{11}$. El penúltimo emperador de un Imperio bizantino asolado por la amenaza otomana recopila una serie de discusio-

9 Para una aproximación a la vida y pensamiento de Juan de Segovia, citemos el clásico estudio de D. CABANELAS, Juan de Segovia y el problema islámico. Madrid, 1952, y las aportaciones más recientes de A. Echevarría, The fortress of faith. The attitude towards Muslims in fifteenth century Spain, Leiden, 1999.

Io D. Cabanelas, Op. cit., p. 118.

11 Manuel II Paleólogo, Entrefiens avec un musulman. $7^{7}$ Controversie. París, 1966.

Proyección internacional de la iglesia hispana Hispania Sacra 51 (1999) 
nes reales que tuvieron lugar en esta ciudad del Asia Menor durante una campaña de inviemo hacia el año 1390. Manuel II emplea en la diatriba un método basado en el derecho y la razón natural, como más tarde hará en España Juan de Segovia. A través de él va exponiendo las excelencias de su fe frente a las argumentaciones del musulmán, de tal manera que, aunque rechaza el Islam, no se permite reflexiones injuriosas sobre él. En realidad, no se pretende mostrar la autenticidad del credo cristiano frente a la falsedad del Islam, sino que los dos interlocutores establecen exposiciones paralelas en las que cada uno desea demostrar las verdaderas esencias de su fe. En este sentido, su discusión transcurre pacíficamente por temas como el amor a los enemigos, la pobreza voluntaria o la virginidad y el celibato. Manuel II y el Mudarris están abogando por la discusión pacífica de las doctrinas, buscando, más que las divergencias, los puntos de contacto, como es su visión común sobre el origen divino pero carácter imperfecto y provisional de la ley de Moisés. El musulmán, incluso, considera buena la ley de Cristo, pero tiene defectos que la hacen impracticable para el ser humano, como es su exceso de rigor y exigencias, a to que Manuel II responde diferenciando entre preceptos y consejos dentro de la religión cristiana. Ante las imperfecciones por defecto del Judaísmo y por exceso del Cristianismo, el Islam se presenta como la religión del justo medio, la más perfecta y expresión definitiva de la voluntad de Dios, por ser la última revelada al hombre. Pero para Manuel II el Islam no es perfecto tampoco, como lo demuestra que base gran parte de su doctrina en los preceptos mosaicos (por ejemplo en lo referente a la circuncisión), habiendo sido criticados previamente por ambos interlocutores los defectos de la ley de Moisés.

Los diálogos de Manuel II Paleólogo están marcando la pauta a otra importante recopilación de discusiones entre fieles del Cristianismo y de la ley islámica que se gesta en el oriente europeo, aunque ésta otra tiene lugar casi un siglo después en una Constantinopla ya en poder otomano. Un método semejante de aproximación del Cristianismo al Islam al sugerido por el Paleólogo y por Juan de Segovia es propuesto por Jorge Ameruzes de Trebisonda, agente diplomático para la colaboración entre cristianos y otomanos ${ }^{12}$. Los encuentros que mantuvo en la Sublime Puerta con el sultán Mehmet II le inspiraron la redacción de una obra en la que apuesta por la posibilidad de un Cristianismo en convivencia con el Islam, pues, a su juicio, ambas culturas pueden desarrollarse de manera pacífica aceptando influencias recíprocas. Para Ameruzes, al igual que para los autores occidentales como Segovia, también es fundamental acceder a los postulados básicos de cada una de las dos doctrinas, siendo mucho más beneficioso centrarse en la búsqueda de puntos en común que en las

12 Vid. al respecto el reciente artículo de O. CRUZ DE LA PALMA, "El Dialogus de Fide de Jorge Ameruzes de Trebisonda. Un mensaje político en el proemio", Hispania Sacra, 51 (1999), pp. 101-118. 
cuestiones divergentes. Conceptos como la Trinidad o la Encarnación, prioritarios en la polémica islamo-cristiana, son analizados en la obra de este autor, que aboga por un acercamiento entre las dos religiones, que será mucho más fructífero que recurrir a nuevas cruzadas o a un enfrentamiento abierto entre otomanos y latinos. Aunque su propósito no encontró eco ni siquiera en la mente del sultán, y el Imperio otomano acabara absorbiendo los rasgos distintivos de la cultura bizantina, lo cierto es que su Dialogus demuestra cómo esta segunda mitad del siglo XV marcó un hito en la evolución de la polémica religiosa al consolidar esta línea de aproximación al Islam con representantes al uno y otro extremo del continente europeo.

En realidad, autores como Juan de Segovia o Jorge Ameruzes lo que están haciendo no es sino intentar una política de sincretismo religioso entre Cristiandad e Islam que consiga resolver el problema de la coexistencia de las dos doctrinas en las latitudes europeas en las que han entrado en confrontación. Este sincretismo se muestra 'como la gran alternativa a la tradicional lucha

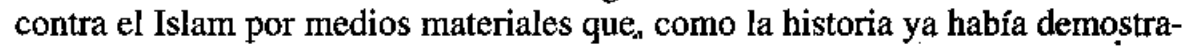
do en el caso de la Península Ibérica, podía suponer largos siglos de guerras que no conducían sino al desgaste de los dos bandos en conflicto sin establecer ninguna solución para el verdadero problema que latía en el fondo. De alguna manera, estos intentos influyen en los textos y acciones de principios del siglo XVI y a estos y otros autores les corresponde el mérito de haber trazado el camino a seguir, o por lo menos, de haberlo desbrozado. Este camino serfa continuado en las décadas siguientes y no sólo por teólogos y filósofos cristianos, como veremos, sino por la propia cultura musulmana, que ve en este sincretismo la única solución a una convivencia pacífica entre las dos religiones en un mismo territorio. Ahí tenemos para demostrarlo los ejemplos que nos proporcionan el Evangelio de San Bartolomé y los plomos de Sacromonte, ambos como creaciones debidas a la cultura morisca que permanece en la Península como reducto y recuerdo de una presencia musulmana prolongada durante ocho largos siglos. Sólo dentro de una comunidad criptomusulmana de estas características es posible generar unos textos como los que empiezan a salir a la luz en Granada a partir de $1588^{13}$. En ellos, los intentos de sincretismo son debidos a la pluma de una élite cultural morisca que intenta hacer valer los presupuestos doctrinales del Islam a través de sus evidentes conexiones con el Cristianismo. Esta aproximación a la fe cristiana traería implícita una dignificación del universo musulmán, a la vez que abriría paso a una eficaz convivencia entre ambas culturas. Sólo en un contexto como en el que se generan estos plomos puede aparecer un texto de las connotaciones que guarda El

13 M.J. Hagerty. Los libros plúmbeos del Sacromonte. Madrid, 1980, J. CaRo Baroja. Las falsificaciones de la Historia (en relación con la de España). Madrid, 1992.

Proyección intemacional de la iglesia hispana

Hispania Sacra 51 (1999) 
Evangelio de San Bartolomé, recogiendo una tradición que relaciona este antiguo evangelio apócrifo con diferentes comunidades heréticas o próximas a la herejía que surgen en la Europa medieval. Su autor también propone un peculiar sincretismo, en el que queden engarzadas las religiones cristiana e islámica. Con el mismo propósito de relatar la única verdad doctrinal, este auténtico texto evangélico islámico también, como hacen los debidos a plumas cristianas, intenta desbrozar los errores de ambos credos, estableciendo el verdadero mensaje de Cristo que no es otro que «la fe eterna de Dios, que los hombres, antes y después de Jesús, se han obstinado en alterar y que solamente el Islam, mediante la revelación de Muhammad, ha mantenido. El apóstol Bernabé, entonces, va a presentar al Islam desde una perspectiva protoislámica para mostrar, con el testimonio de la verdadera vivencia y mensaje de Jesús, dónde está la voluntad de Dios» ${ }^{14}$.

La existencia de este núcleo morisco en la España del XVI marca de una forma patente la evolución de la polémica generada en este estado moderno a lo largo de toda la centuria. Tras la toma de Granada en 1492, España se presenta a los ojos de Europa y del resto del mundo conocido como verdadera «religión triunfante», relegando incluso al propio Papado como cabeza tradicional de la lucha contra los enemigos de la Iglesia. Los Reyes Católicos primero y los Austrias después, encarnarán a la perfección el papel de monarcas defensores de la Cristiandad que, inspirados por Dios, llevan a cabo una política que busca la definitiva derrota del infiel por las armas. Con este argumento se justifica, por ejemplo, la conquista del norte de África, en la que éxitos como la toma de Orán por el cardenal Cisneros en 1509 se explican por la protección y eficacia inspirada por Dios.

Desde su posición de triunfo frente al Islam conseguida tras largos siglos de enfrentamiento, España asume el papel de defensora de los postulados más clásicos de la polémica islamo-cristiana, acercándose a toda una tradición de polemistas que, como Pedro el Venerable, fueron estableciendo los presupuestos fundamentales de la diatriba teológica. Aunque se hacen esfuerzos para atraer a los moriscos y, en alguna medida, se busque la asimilación, siempre se les acaba diferenciando, siendo los propios moriscos los primeros interesados en presentarse como una comunidad distinta a la cristiana. Los temas polémicos que separan a los cristianos de los moriscos en el transcurso del Quinientos, según estudió L.Cardaillac ${ }^{15}$, son los mismos que los que se discutieron con fruición en los siglos medievales, si bien ahora nos encontramos con una polémica soterrada, al estar prohibida una de las dos confesiones. La Trinidad, como ataque a la unicidad de Dios, fundamento de la religión islámica,

14 L.F. BERNABÉ PONS. El texto morisco del Evangelio de San Bartolomé. Granada, 1998, p. 18.

15 L. CARDALLAC. Moriscos y cristianos. Un enfrentamiento polémico, 1492+1640. Madrid, 1979. 
es motivo de continua fricción. Para los musulmanes, los cristianos, si creen en la Trinidad, son politeístas, y como los principales responsables de la creencia en este dogma son los papas, se va especialmente contra ellos. Tampoco admiten los moriscos la divinidad de Cristo, subrayando su humanidad, de la misma forma que niegan la Encarnación de un Dios hecho hombre, la virginidad de María o la crucifixión del propio Jesús. En realidad, muchos de estos temas de discusión coinciden abiertamente con los que se están planteando en Trento a partir de 1545, porque son los mismos que los que están criticando los protestantes desde el inicio de la Reforma. Esto se puede ver en el caso del tema de la Iglesia, sobre la que protestantes y moriscos coinciden en observar serios problemas que la alejan de sus primitivos cometidos habiếndola transformado en una institución de carácter puramente formal. El rechazo a algunos sacramentos por considerarlos vanas supersticiones y el ataque a manifestaciones externas de religiosidad como el culto a las imágenes, las indulgencias y jubileos unen también a ambas comunidades en su oposición a la doctrina cristiana tal y como estaba establecida. Fruto de estos contactos entre el credo reformado y el morisco son autores como Cipriano de Valera, primer traductor al castellano de la Biblia, que advierte los signos de proximidad entre los dos grupos y que se lanza a escribir un tratado para enseñar la conducta que los protestantes que fueran hechos cautivos en Berbería debían mostrar respecto a católicos, musulmanes y judíos ${ }^{16}$. Aún situándose en contra del Islam, no duda en poner a sus seguidores como ejemplos de denuncia de los errores cometidos por los cristianos en la práctica de su fe. Valera, a su vez, servirá de inspiración a los autores moriscos, aunque éstos utilicen los argumentos protestantes en la orientación que más les interesa ${ }^{17}$. En este sentido, los moriscos fueron acusados en alguna ocasión por los católicos de intentos de sincretismo con el protestantismo, y en realidad cabe advertir influencias entre ambas doctrinas, pero nada más.

De la misma forma, se puede apreciar la existencia de contactos entre las ideas religiosas de los moriscos y las defendidas por otra de las corrientes espirituales en boga en las primeras décadas del XVI en los estados modernos del Occidente europeo, los erasmistas. Los seguidores del Islam de un mayor nivel cultural conocen los textos de Erasmo, Vives o Valdés, de tal manera que los temas y críticas que hacen a la Iglesia y a los fundamentos teológicos del Cristianismo coinciden en más de una ocasión. Sin embargo, lo que pretenden unos y unos es bien diferente, pues mientras que los erasmistas hacen la crítica con un sentido constructivo, buscando una vuelta de la religión cristiana a sus 1872 .

16 C. DE VALERA. Tratado para confirmar en la fe cristiana a los cautivos de Berberia. Madrid,

17 L. CardallLaC. Op. cit., pp. 124-130.

Proyección internacional de la iglesia hispana Hispania Sacra 51 (1999) 
esencias evangélicas, los moriscos se sitúan del lado del juicio más destructivo, plasmando un Cristianismo plagado de abusos, mentiras y mezquindad sin posibilidad de solución ${ }^{18}$.

La España que hunde sus raíces en el Quinientos, al considerarse dueña del triunfo más relevante sobre el Islam hasta la fecha y por su propia asunción de la defensa de los postulados más clásicos de la polémica, se aboca a una imprescindible labor de conversión de la minoría morisca. En este horizonte se inscriben la mayoría de los textos polémicos escritos por autores cristianos en la primera mitad del XVI. Autores como Martín García ${ }^{19}$, Juan Andrés ${ }^{20} 0$ Bemardo Pérez de Chinchón ${ }^{21}$, escriben obras en las que, sin dejar de lado los presupuestos tradicionales de la diatriba contra el Islam, se imbuyen de un espíritu misional propio del momento, consiguiendo al mismo tiempo una autoafirmación del propio credo cristiano. Los sermones de Martín García se acabarán convirtiendo en obra de referencia para el adoctrinamiento de los musulmanes a lo largo de todo el siglo XVI, mientras que los escritos de Juan Andrés se imbuyen de un fuerte didactismo en el que se intenta acercar el cristianismo a los seguidores del Islam de la forma más pedagógica posible. Según afirma M. Á. de Bunes Ibarra, los textos a partir de los cuales se intenta catequizar en la España de la primera mitad del XVI, «deben conjugar los argumentos tradicionales de la polémica, su base teológica para desmontar la religión de los seguidores de Mahoma, con la casuística más cercana a la vida cotidiana, para convencer a sus oyentes de los errores que practican y creen. Este doble planteamiento de la cuestión es lo que hace diferente a la literatura anti-islámica de la que se está escribiendo en la misma época por otros eclesiásticos, tanto españoles como europeos, hasta $1540 »^{22}$. Existe la conciencia de que los moriscos se pueden convertir al Cristianismo de verdad, en con-

18 También es posible advertir cómo el interés en la polémica cristiana contra el Islam aparece en autores erasmistas que intentan seguir la línea de aproximación a la cultura y religión musulmana como fórmula para proceder al adoctrinamiento de sus fieles. Nicolás Clenard, erasmista belga de la primera mitad del siglo XVI, acude a Salamanca, donde Hernán Núñez le instruye en el aprendizaje del árabe tras de lo cual marcha a Marruecos con proyectos evangelizadores. Vid. K. WAGNER, "Nicolás Clenardo. Andanzas de un humanista belga en España y Portugal". Actas de las Jornadas Hispano Belgas, Sevilla, 1992.

19 M. GARCIA, Sermones eminentissimi totiusque Barchinonensis gregis tutatoris acerrimi: necnon immarcesibilis sacre teologie palidamento insigniti Martini Garcie. Zaragoza, 1517.

20 J. ANDRÉs, Libro nuevamente impreso que se llama confusión de la secta mahomática y del alcorán. Valencia, 1515.

2I B. PEREZ DE CHINChÓN. Libro llamado antialcorán. Valencia, 1532.

22 M. Á DE BUNES IBARRA. "La evolución de la polémica anti-isiámica en los teólogos españoles del primer Renacimiento", en H. SANTIAGO-OTERO, Diálogo filosofico-religioso entre el Cristianismo, Judaísmo e Islamismo durante la Edad Media en la Península Ibérica. Actas del Coloquio Internacional de San Lorenzo de El Escorial, 1991. Bélgica, Brepols, 1994. 
ciencia, y para ello es fundamental que la iglesia cristiana les acerque la única religión auténtica, convenciéndoles de la falsedad del Islam, pero haciéndolo con la palabra y no con las armas. Prioritario para conseguirlo será recuperar los comportamientos de siglos pasados en lo que se refiere a subrayar la necesidad de proceder al conocimiento del árabe y de los textos islámicos por parte de quienes se van a dedicar a la evangelización, tanto la más práctica, en contacto directo con los musulmanes, como la que se hace a partir de los libros. Esta aproximación al universo cultural y religioso de los seguidores del Islam vendrá, en buena medida, avalada por el propio Concilio de Trento, que estima necesario partir de este punto previo para conseguir el éxito en la labor evangelizadora.

Todos estos textos están escritos desde el concepto de superioridad cristiana sobre la religión musulmana que se ha venido gestando conforme avanzaba la reconquista y que se ha consolidado tras el éxito final de 1492. Sólo desde este punto de vista pueden entenderse unos escritos que se afanan en poner de manifiesto lo absurdo de las creencias de aquellos a quienes se pretende evangelizar, si bien es cierto que se aprecia una importante evolución entre los textos de las primeras décadas del Quinientos, aún imbuidos de un espíritu optimista respecto al éxito de esta labor misional, y los realizados en los años centrales y finales del siglo, en los que el desaliento se hace cada vez más presente. En esta evolución de nuevo tendría un papel muy significativo el Concilio de Trento, donde la Iglesia cristiana, que ha sufrido el embate de la reforma luterana, deja a un lado su confianza en la lucha pacífica contra las minorías religiosas y opta por proceder mediante unos métodos más expeditivos. Ello, en el caso de los moriscos supone que se les deje de ver como un grupo asimilable siempre y cuando se lleve a cabo una adecuada labor evangelizadora y se les vuelva a considerar como en los siglos medievales como un adversario religioso que, además, puede traer graves complicaciones a España a causa de sus interconexiones con los berberiscos de la otra orilla del Mediterráneo y con la propia Sublime Puerta. Con todo ello, los textos polémico-evangelizadores de las primeras décadas del XVI se van convirtendo en escritos cargados de una gran violencia verbal contra el musulmán conforme avanza el siglo (Lope de Obregón ${ }^{23}$ ), y los pocos que aparecen al final de la centuria y principios de la siguiente se consolidan como auténticas reprobaciones hacia la doctrina islámica y justificaciones de cara a la expulsión de los moriscos (J. Bleda ${ }^{24}$, P. Aznar Cardona $\left.{ }^{25}\right)^{26}$.

${ }^{23}$ L. DE OBREGÓN, Confutación del Alcorán y secta mahometana, sacado de sus propios libros y de la vida del mesmo Mahoma. Granada, 1555.

24 J. BLEDA, Crónica de los moros de España. Valencia, 1618.

25 P. AZnAR CARDONA, Expulsión justificada de los moriscos españoles y suma de las excellencias de nuestro rey don Felipe el Católico Tercero de este nombre. Huesca, 1612.

Proyección intemacional de la iglesia hispana Hispania Sacra 51 (1999) 
El desarrollo práctico de la polémica entre Cristiandad e Islam en la España de las primeras décadas del Quinientos demuestra la continuidad entre lo que se gestó en la transición del medievo al renacimiento y los comportamientos que aparecen cuando, tras las conversiones forzosas de muchos musulmanes a partir del edicto de 1502 , el tema de la evangelización sea prioritario. Buen ejemplo de ello son figuras como Hernando de Talavera, arzobispo de Granada, quien abrirfa el camino a quienes, dejando a un lado los escritos polémicos propiamente dichos, ponen en práctica los postulados que esta diatriba, vista desde el lado más tolerante, lleva predicando desde décadas atrás. Talavera encarga a Pedro de Alcalá la elaboración de un vocabulario y una gramática árabe para la instrucción de tos eclesiásticos que luego han de llevar la doctrina cristiana a los moriscos granadinos, además de ser el autor de la Breve Doctrina y enseñanza que se ha de saber y poner en obra todo cristiano y cristiana, en la que pretende acercar de manera asequible el credo cristiano a estos musulmanes. Por su parte, Martín de Ayala, arzobispo de Valencia, encarga la redacción de la Doctrina christiana en lengua aráviga y castellana, como texto a utilizar en las catequesis de los moriscos valencianos. Figuras como Talavera o Ayala demuestran el interés con el que la Iglesia abordó los presupuestos de aproximación al Islam directamente heredados del espíritu conciliador de autores anteriores como Ramón Llull o Juan de Segovia, si bien éste desechó la tarea misional por considerarla larga en exceso y no demasiado práctica para los fines que se pretendía alcanzar. El ideal que inspira las obras y la labor de catequización que alientan personas como Talavera o Ayala es el de que la superioridad del Cristianismo sería comprendida sin dificultades en cuanto se enseñase la doctrina a los musulmanes. Por ello estos escritos no abundaban en la resolución de posibles dudas y malentendidos que pudieran surgir a los fieles al Islam durante las sesiones de catequesis, recurriéndose cuando esto ocurría al enunciado del argumento de autoridad que ponía fin a la discusión ${ }^{27}$. Frente al optimismo evangelizador que representa esta postura se sitúa el mayor pesimismo del mundo jesuítico. Bien es cierto que los jesuitas también empiezan valorando la necesidad de adoctrinar a los musulmanes y creen que esto se conseguiría fácilmente por la superioridad del Cristianismo, como muestra el propio San Ignacio de Loyola al defender una política de fundaciones de colegios y envío de religiosos de esta orden a las zonas en las que se está produciendo la expansión del Islam en las primeras décadas del

26 Sobre la evolución de los textos polémicos espaffoles a lo largo del siglo XVI y XVII, vid., M. A. DE BUNES IBARRA, "El enfrentamiento contra el Islam en el siglo de Oro: los antialcoranes", Edad de Oro, VIII (1989), pp. 41-58.

27 L. CARDallLaC, Op. cit., p. 46-47. 
siglo $\mathrm{XVI}^{28}$. Sin embargo, la recepción de las ideas extraídas al hilo de la celebración de las diferentes sesiones del concilio tridentino, unido a su visión más ontológica de la polémica contra el Islam, acaba situando al jesuitismo en una posición más pesimista con respecto a la evangelización de musulmanes que termina por situar a esta orden en un segundo plano dentro de la tendencia misional de la Iglesia cristiana en la primera mitad del Quinientos.

La evolución del enfrentamiento entre la Europa cristiana y el Imperio otomano a lo largo del siglo XVI marca en buena medida los derroteros que esta polémica anti-islámica va a seguir en las décadas finales de la centuria. La amenaza del Islam sigue presente y pujante en Europa por tierra y mar, y cada vez se hace más evidente que será muy difícil pararla, como demuestra la fuerza con que se mueve en los territorios norteafricanos o con los continuos ataques de su armada a posiciones estratégicas del Mediterráneo central. Pronto afectará esta mentalidad cristiana a la diatriba religiosa, poniéndose coto a los presupuestos más tolerantes 'de acercamiento al Islam que habían inspirado muchos de los escritos y actuaciones de las primeras décadas del Quinientos. España también asume como propio este pesimismo, considerando fracasada su labor de adoctrinamiento del infiel, como demuestra que los moriscos sigan practicando el credo musulmán y se hayan convertido en la quinta columna del Imperio otomano en Occidente. Desde una perspectiva común al resto de los estados europeos, España reconvierte hacia la intolerancia su postura mayoritaria en lo que a la polémica anti-islámica se refiere, poniendo fin a los intentos de aproximación entre la Cristiandad y el Islam.

28 M. Á. de Bunes IBARRA, "San Ignacio de Loyola y la expansión del Islam en el siglo XVI", Anuario del Instituto de San Ignacio de Loyola, 1995, pp. 93-105.

Proyección internacional de la iglesia hispana Hispania Sacra 51 (1999) 